\title{
Towards Achievement of Gender Parity in Decision Making? Experience from the Participation of Male and Female MPs in the Parliament of Tanzania
}

\author{
Idda Lyatonga Swai (Corresponding author) \\ Department of Local Government Management, School of Public Administration and \\ Management, Mzumbe University
}

Orest Sebastian Masue

Department of Public Service and Human Resource Management, School of Public Administration and Management, Mzumbe University

Received: Jan. 6, 2019 Accepted: Feb. 11, 2019 Online published: Mar. 1, 2019

doi:10.5296/jpag.v9i1.14180 URL: https://doi.org/10.5296/jpag.v9i1.14180

\begin{abstract}
There have been gradual efforts to increase the number of female MPs in Tanzania through women empowerment creation of quotas (special seats) to enable them play an active role in this important decision making body. This article seeks to find out whether the increase in number of women MPs in the Tanzanian Parliament has influenced women's degree of intervention in terms of: (1) asking basic questions; (2) asking supplementary questions; and (3) making contribution to parliamentary discussions. We obtained data from the official website of the Parliament of Tanzania, and analyzed them through descriptive statistics and multiple linear regression analysis. The results suggest that an increase in number of female MPs will increase their level of intervention; hence, we are inclined to the conclusion that numbers matter in determining female MPs' influence in the Parliament.
\end{abstract}

Keywords: MPs intervention, basic question, supplementary question, making contribution, Tanzanian legislature, special seats, women quotas

\section{Introduction}

During the United Nations Fourth World Conference on Women (FWCW) held in Beijing, China, from September $4^{\text {th }}$ to $15^{\text {th }}, 1995$, equal participation of men and women was one of the main issues in the agenda that were discussed and agreed upon. Tanzania, as one of the UN members also signed the Beijing declaration which aimed at taking deliberate measures 
to ensure achievement of women's rights in the country through increasing their number at different levels of decision making, such as Boards of Directors, Heads of Institutions, Commissioners and National Delegations.

Equal participation of citizens is a requirement as per Article 21 of the Constitution of United Republic of Tanzania that every citizen of the United Republic of Tanzania has the right to participate in the governance of the country, either directly or through their representatives (URT, 1998). This provides the basis for female participation in all spheres of life in society. Equal participation for men and women in the decision making was further reinforced by the Millennium Development Goals (MDGs), endorsed in 2000, as part of the internationally agreed development goals in the General Assembly of the United Nations (UN). This is emphasized in the MDGs number 3 which focused on promoting gender equality and empowers women and girls (Swai, 2017). The target of this millennium goal among others includes the elimination of gender disparity at all levels of education, the equal sharing of power between men and women in decision-making bodies, equality of pay for men and women, especially in the non-agricultural sectors (Swai, 2017).

In order to pursue this ambition, the government has shown its commitment through Cabinet Decision No. 23 of 1996 (Kamugisha \& Ringo, 2013). Apart from that, the government has shown other forms of commitment, which reinforce equality of men and women in decision making. These include ratification of the UN Convention on the Elimination of all forms of Discrimination against Women (CEDAW), the Universal Declaration of Human Rights; ratifying SADC's protocol on gender and development and the introduction of quota system to enhance representation of varied interests in the decision making (Swai et al, 2013; Meena, 2003;2009; Yaliwe et. al, 2013). This has been accompanied by change in the country's laws, regulations and policies that was followed by the affirmative action by the government has led to the increase in the number of women in all levels of decision making including the parliament which is the decision making body at the national level (Warioba \& Fussi, 2012).

In terms of numbers, as of January 2013, the situation was that out of the 351 MPs, 128 (36\%) were women; of whom $25(7 \%)$ were directly elected from constituencies and 103 (29\%) were appointed under the special seats arrangements. In the 2015 election, of 389 MPs, 113 MPs were the special-seat appointed through the quota system, while 27 were female MPs who were directly elected from the constituency. Insofar as the statistical data inform us, we are inclined to the argument that women representation in Tanzania has increased significantly in the last ten years (Swai, 2017). The gradual increase in numbers is expected to change the social-cultural setback against women representatives in the parliament. This suggests that an authentic women participation or representation may not be reflected in numbers alone. Rather, it can be demonstrated in terms of how much they have opportunity to participate in the decision making by making attempts to influence the decision making (Alsop, et al, 2006). In order to 'argue beyond numbers' on the extent to which women representation in the parliament has increased their participation in decision making bodies, it is important to go further than just counting the number of women and men representatives. The value of the voice raised by women in the decision making is important indicators for women representation in the decision making. This article seeks to answer the question on 
how the increased number of women MPs in the parliament has increased their participation relative to male representatives.

\section{Methodology}

Our paper is based on a desk review study, where data were gathered through internet searching from the public parliamentary on-line information system (POLIS) of the parliament's website ${ }^{1}$ using search 'key words'. The key words used were; elected members of the parliament, appointed MPs, basic questions, supplementary questions and MPs' contributions. The data were from the parliament sessions that were held between 2010 and 2014 and the last search was done in March, 2014. The actual number of MPs was 352 but the number of (MPs) involved in this study was 347 (126 female and 221 male) because five MPs including the speaker, deputy speaker and the three parliamentary chairpersons were not included in the sample because they seemed to have opportunity to make more interventions than other MPs in virtue of their positions which could lead to outlier effect in the data. We created a data matrix as a tool for analyzing our data. In doing this, we developed an excel sheet showing the list of all MPs ,their respective political parties, gender, constituency, status (elected or appointed), education level, number of basic and supplementary questions asked and contributions made. The analysis involved descriptive statistics to show the distribution of the MPs' interventions and finally linear regression to identify the factors that explain the MPs' differences in making interventions.

\section{Results}

This section present the findings based on our research question on how the increased number of women MPs in the parliament has increased their participation as compared to male representatives. In answering this question, we started with the descriptive analysis on the general distribution of the MPs in terms of male and female intervention in three categories of asking basic questions, supplementary questions and making contributions in the discussion during the debate. And then, we culminate the results section by indicating the factors which explain the MPs interventions.

\subsection{Distribution of MPs Interventions by Category}

As clarified in the previous sections, the MPs interventions were basically categorized into three categories of asking basic and supplementary questions and making contributions. The descriptive analysis was performed to know the distribution of the MPs interventions in the three categories before comparing male and female MPs' interventions in these categories. What we present in table 1 are just descriptive statistics showing patterns of the data in terms of MPs' interventions in the three categories of interventions.

\footnotetext{
${ }^{1}$ www.parliament.go.tz/
} 
Table 1. MPs interventions during the period between 2010 and 2014

\begin{tabular}{|c|c|c|c|}
\hline $\begin{array}{l}\text { Category } \\
\text { intervention }\end{array}$ & $\begin{array}{c}\text { Number of } \\
\text { interventions }\end{array}$ & $\begin{array}{c}\text { Average } \\
\text { interventions }\end{array}$ & Percent \\
\hline Basic questions & 2,154 & 6.21 & 9 \\
\hline $\begin{array}{l}\text { Supplementary } \\
\text { questions }\end{array}$ & 3,862 & 11.13 & 17 \\
\hline Contributions & 17,285 & 49.81 & 74 \\
\hline Total & 23,301 & 67.15 & 100 \\
\hline
\end{tabular}

The pattern of the results in table 1 indicates that the MPs interventions were dominated by interventions in the category of contributions to the parliamentary debate/discussion sessions. As shown in the data in table 1 , contributions accounted for $74 \%$ of all the interventions. The trend suggests that generally MPs make more contributions to the parliamentary discussions than asking questions. The data show that only $9 \%$ of all interventions made in the category of asking the basic questions, while $17 \%$ of all interventions were in the category of supplementary questions.

We also did a comparison of the MPs' interventions on the basis of gender to find out if it had any association with their degree of intervention. Specifically, we wanted to examine some variations between male and female MPs in terms of asking basic and supplementary questions and contributing to the parliamentary discussions. The first category of interventions that we examined was basic questions. These are the major means that the MPs use to scrutinize the government. Basic questions are usually prepared in writing by the respective MP early in advance and submitted to the government before the parliamentary session to provide sufficient time for ministers to prepare answers for the government during a particular parliamentary session.

Table 2. Intervention of MPs in asking basic questions by gender

\begin{tabular}{lcc}
\hline Dimension & Female MPs $(\mathbf{n}=\mathbf{1 2 6})$ & Male MPs $(\mathbf{n}=\mathbf{2 2 1})$ \\
\hline Number of basic questions & 810 & 1344 \\
Percent & $38 \%$ & $62 \%$ \\
Average basic questions & 6.43 & 6.08 \\
\hline
\end{tabular}

There are some indications that there is a difference between male and female MPs in the category of asking basic questions. The performance of male and female MPs was compared through the average interventions for each group. Although the results in table 2, the male MPs have more interventions in terms of number than the female MPs, the average intervention of female MPs is higher than that of male MPs. This means that the female MPs participated more in the category of asking basic questions than male MPs.

The second category of interventions which we examine in this paper as a measure of participation of MPs is the number of supplementary questions asked. These include all additional questions asked by MPs following an unsatisfactory response by the government to a basic question or a satisfactory answer to the same which creates an additional question related to the basic one. An opportunity to ask a maximum of two supplementary questions is 


\section{Mll Macrothink}

Journal of Public Administration and Governance

ISSN 2161-7104

2019, Vol. 9, No. 1

first given to the MP whose basic question has been addressed, and then other MPs who might have questions consequent to the response of the government on the particular basic question are invited to ask no more than one supplementary question. All supplementary questions are usually answered by the government through the respective deputy ministers and /or ministers' on the spot after they have being posed.

Table 3. Supplementary questions of MPs for the period of 2010-2014

\begin{tabular}{lcc}
\hline Dimension & Female MPs $(\mathbf{n}=\mathbf{1 2 6})$ & Male MPs $(\mathbf{n}=\mathbf{2 2 1})$ \\
\hline Number of & & \\
questions & 1421 & 2441 \\
Percent & $37 \%$ & $63 \%$ \\
Average contributions & 11.28 & 11.04 \\
\hline
\end{tabular}

Average supplementary questions for male and female is the number of supplementary questions divide by the number of male and female MPs respectively.

Table 3 presents results on the differences between male and female MPs in the number of supplementary questions asked. The results indicate that female MPs had a slightly higher average index in supplementary questions than male MPs, implying that male MPs made a fewer supplementary questions than did the female MPs. This reflects a higher degree of participation for women MPs than for the male MPs. This observation suggests that female MPs were more active in asking supplementary questions than male MPs.

The final category that was used to measure actual participation of the MPs in parliamentary sessions was 'contribution'. Contribution in this article refers to comments made by individual MPs on ongoing parliamentary discussion/debate. Basically, a contribution is not a formal question. Rather, it is a general remark, an observation during debate or a comment on a tabled bill of a proposed legislation.

Table 4. Contributions made by MPs between 2010 and 2014

\begin{tabular}{|c|c|c|}
\hline Dimension & $\begin{array}{l}\text { Female MPs }(n= \\
126)\end{array}$ & Male MPs $(n=221)$ \\
\hline Number of Contributions & 5,676 & 11,609 \\
\hline Percent & $33 \%$ & $67 \%$ \\
\hline Average contributions & 45.05 & 52.53 \\
\hline
\end{tabular}

The results in table 4 show some indications that there are some differences in contributions made by male and female MPs in the period between 2010 and 2014. The average contribution for the male MPs was higher than the average contributions by the female MPs. This trend suggests that male MPs participated more in making contributions than female MPs.

\subsection{Factors Explaining the Variations in Interventions}

Further analysis was performed to find out the factors that explain the differences found between male and female MPs intervention in parliamentary debate. The results in table 5 
show that the MPs' intervention through contributions was explained by leadership position, institutional position and affiliation to a political party; whilst the MPs' intervention through asking basic and supplementary questions were explained by leadership position and political party affiliation. The results however showed that education level was not a determinant of any of the three categories of MPs' interventions.

Table 5. Determinants of MPs'interventions

\begin{tabular}{lcccccc}
\hline & \multicolumn{3}{c}{$\begin{array}{c}\text { Supplementary } \\
\text { questions }\end{array}$} & \multicolumn{2}{c}{ Basic questions } \\
\cline { 2 - 7 } Predictors & $\mathrm{B}$ & $\mathrm{p}$-value & $\mathrm{B}$ & $\mathrm{p}$-value & $\mathrm{B}$ & $\mathrm{p}$-value \\
\hline Education level & -0.03 & 0.58 & -0.04 & 0.44 & -0.03 & 0.62 \\
Leadership Position & 2.48 & 0.01 & -0.12 & 0.02 & -0.14 & 0.01 \\
Institutional position & 0.112 & 0.03 & 0 & 0.92 & -0.02 & 0.7 \\
Affiliation to a political party & -0.18 & 0.001 & -0.29 & 0.001 & -0.29 & 0.001 \\
\hline
\end{tabular}

Regression coefficient denoted by symbol $B$ describes the spreading magnitude of the factors to the MPs interventions. A larger regression coefficient implies strong effect and vice-versa. Positive regression coefficient indicates a strong effect to MPs interventions while a negative regression coefficient indicate decrease of the MPs interventions as the factors change.

The interventions of the MPs who were the ministers were compared to the interventions of the MPs who were not ministers. The results as indicated in table 5 show that the MPs who were the ministers made more interventions in the category of contribution than the MPs who were not ministers. This observation suggests that being a minister increases the chance of an MP to make more contribution by a factor of 2.48 as compared to not being a minister. Similarly, leadership position had inverse relation with the MPs interventions in the categories of basic and supplementary questions. The MPs who were not ministers made more interventions in the categories of asking basic and supplementary questions than those who were ministers. Being a minister decreases one's chance of asking basic questions by a factor of -..12 as well as the probability of asking supplementary questions by a factor of -.14. This means that the MPs who were not ministers asked more questions than the MPs who were ministers. This was an obvious observation since the traditional role of ministers in the parliament is to respond to the questions asked by MPs on behalf of the government.

Regarding the institutional position, the interventions of elected MPs were compared with the interventions of the appointed MPs through the women's special-seats arrangement. The results shown in table 5 indicate that the MPs who are elected through their constituencies made more interventions in the category of contributions than those who were appointed through the women's special-seat arrangement. Being an elected MP increases the probability to make more interventions in contribution by a factor of .112 as compared to being a special-seat female MP. This observation concurs with that by Yoon (2011) who argued that the performance of female MPs under special-seats arrangement in Tanzania is overshadowed by the work of constituency MPs who tend to monopolize the opportunity of intervening development-related issues in their constituencies limiting the intervention by special seat MPs. It was also noted that the special-seat-female-MPs had a marginally higher probability 
to make interventions in the categories of basic and supplementary questions, but the difference was not significant. Therefore, being in elected position has significant effect only in the category of contributions, but not in the categories of basic and supplementary questions.

The interventions by the MPs CCM (the ruling party) were compared to the interventions of the MPs of the opposition parties. The results (see table 5) indicate that the MPs from the opposition parties made more interventions in all categories than the MPs from the ruling party. The chance to make intervention of MPs of the ruling party is lower by a factor of -.18 in contributions, -.29 in basic questions and -.29 in supplementary questions when compared to the MPs from the opposition parties. This observation suggests that the MPs who are in the opposition camp have a higher chance of making more interventions in all categories of intervention than the MPs of the ruling party.

\section{Discussion}

Our primary goal in this article is to compare male and female MPs' participation in the parliament in terms of the number of interventions they make in terms of asking basic questions, supplementary questions and making contributions to parliamentary discussions. The results show that male MPs made more interventions in the category of contribution to parliamentary discussions than did the female MPs. This observation suggests that male MPs had more influence in this category of interventions than the female MPs. When it comes to performance of MPs in asking basic questions; the results indicate that female MPs performed better than male MPs by having higher number of interventions than their counterparts - male MPs. The same trend was observed in the category of asking supplementary questions, where female MPs appeared to perform better than male MPs. These results support those of the study by Yoon (2011) that suggest that the growth in women legislative in Tanzania has positively affected parliamentary debate atmosphere and policy outcomes in Tanzania. According to Yoon (2011), the majority of the MPs held the view that the proportion of female MPs interventions to parliamentary debates has significantly increased due to the increased women representation. The same result was found at local government level where female councillors made more interventions in the decision making than male councillors. According to Swai (2017), the elected female councillors participate and ultimately have more influence than male and special seat female councillors.

This result concurs with those in other studies such as Meena (2009), Swai (2017) and Yoon (2011) which suggest that the increase in female representatives in the Tanzanian parliament and local councils have gradually changed the long term socio-cultural and setback against female influence in the parliament and local council which is the most crucial national and local decision making body. According to Meena (2009), female numerical representation has transformed the so called male dominated political culture in the parliament of Tanzania. This transformation has led to a remarkable increase in the degree of interaction between male and female MPs in the recent years (Yoon, 2011) a phenomenon which was not quite visible a few years ago both in the parliamentary debates and in the committees. Besides, the increase in the number of female MPs in the Tanzanian parliament has led to a better position insofar as 
the articulation of women issues in the parliament is concerned. With the currently more visible proportion of female MPs, the establishment of women's caucus that among other activities, train women MPs soon after election to build confidence and equip them with techniques to engage in asking questions and contributing fruitfully to parliamentary debates has been made possible. The outcome of this is gradually seen particularly in the aspect asking basic and supplementary questions. This observation also predicts increased visibility of female MPs' participation in the aspect of making contributions to parliamentary debates which is currently less than that of male MPs.

\section{Summary and Concluding Thoughts}

The article focused on examining the participation of male and female MPs by looking into the number and proportion of interventions they make in terms of contributing to parliamentary discussions and asking basic and supplementary questions. The results indicate that there was an explicit variation in the proportion of interventions made by male and female MPs in the Parliament of Tanzania in the period between 2010 and 2014. Male MPs dominated in the aspect of contribution to parliamentary discussions in terms of the proportion of interventions they made (i.e. 67\%) relative to their counterparts - female MPs (33\%). This difference was explained by three main factors: institutional position, leadership position and affiliation to a political party. The MPs who were ministers, the elected MPs and the opposition party MPs had a higher chance to make more interventions in contributions than their counterpart MPs who were not affiliated to these three categories. It was also observed that the categories of asking basic and supplementary questions were dominated by female MPs. Leadership position and political party affiliation were the predictors of MPs' interventions in asking basic and supplementary questions. Being an MP from the opposition or a non-minister MP had a higher probability to make interventions through asking basic and supplementary questions than being a minister-MP or a member from the ruling party.

Based on the results presented above, the paper concludes that the increase in number of female MPs has all the same increased their participation in terms of asking basic and supplementary questions. There is a significant change in the parliamentary debates in relation to the increase in the number of female MPs. This observation suggests that if the number of women in the parliament equals that of men, then female MPs can perform equally or even more than the male MPs.

\section{Policy Implication}

As much as we have seen in the results, the capacity of both male and female MPs in terms of making interventions in the parliamentary sessions is unquestionable. What we have noted to be the most visible challenge in terms of women's influence in the parliament of Tanzania is their low numbers. Thus, an important policy intervention needs to be pursued to address the challenge. The most practical and relevant intervention we suggest pursuant to our observations in this article is to embark on institutional reforms to address the root causes of gender inequality in the legislative bodies. Specifically the reforms should address the constitution, electoral institutions and legislation. In line with the reforms, multi-actor efforts should be directed towards sensitization of both men and women on the socio-economic 


\section{Macrothink}

Journal of Public Administration and Governance

ISSN 2161-7104

2019, Vol. 9, No. 1

importance of attaining 50-50 gender balance at all levels of political representation in the country.

\section{References}

Alsop, R., Bertelsen, M. F., \& Holland, J. (2006). Empowerment in Practice: From Analysis to Implementation: Washington DC: World Bank Publications.

Kamugisha, D., \& Ringo, C. (2013). A Bumpy road towards women participation in Political and Managerial Decision Making: The Perspective of Tanzania. Journal of Policy and Leadership, 1(2), 104-120.

Meena, R. (2003). The politics of quotas in Tanzania. In A paper presented at the International Institute for Democracy and Electoral Assistance (IDEA)/Electoral Institute of Southern Africa (EISA)/Southern African Development Community (SADC) Parliamentary Forum Conference.

Meena, R. (2009). Women Participation in Positions of Power and Influence in Tanzania. In Research and Education for Democracy Conference.

Swai, I. L. (2017). The Relative Participation and Influence of Female Councillors in the Decisions of the Councils in Tanzania. Vakgroep Bestuursrecht \& Bestuurskunde, Groningen.

Swai, I. L., Anasel, G., \& Masue, O. S. (2013). Achievements and Challenges of women special seats Arrangements in Tanzania. Journal of Policy and Leadership, Centre for Policy and Leadership, 2(1), 121-135.

URT, (1998). The Constitution of the United Republic of Tanzania, Dar es Salaam, Government Printer.

Warioba, L., \&Fussi, J. (2012). Engendering Local Government in Tanzania: Fifteen Years after Beijing Conference. Journal of Policy and Leadership, Mzumbe, Tanzania.

Yaliwe, M., Selebogo, P., \& Ojakorotu, V. (2013). SADC gender and development protocol: an evaluation of equality, empowerment and gender based violence in South Africa (2008-2012). Gender and Behaviour, 11(1), 5175-5196.

Yoon, M. Y. (2011). More women in the Tanzanian legislature: Do numbers matter? Journal of Contemporary African Studies, 29(1), 83-98. https://doi.org/10.1080/02589001.2011.539011

\section{Copyright Disclaimer}

Copyright for this article is retained by the author(s), with first publication rights granted to the journal.

This is an open-access article distributed under the terms and conditions of the Creative Commons Attribution license (http://creativecommons.org/licenses/by/4.0/). 